\title{
Effectiveness of an Intervention to Increase Construction Workers' Use of Hearing Protection
}

\author{
Sally L. Lusk, Oi Saeng Hong, David L. Ronis, and Brenda L. Eakin, University of \\ Michigan, Ann Arbor, Michigan, Madeleine J. Kerr, University of Minnesota, \\ Minneapolis, Minnesota, Margaret R. Early, Oakland University, Rochester, Michigan
}

\begin{abstract}
In this project we tested the effectiveness of a theory-based intervention (video, pamphlets, and guided practice session) to increase the use of hearing protection devices (HPDs) among Midwestern construction workers and a national group of plumber/pipefitter trainers. Posttest measures were collected 10-12 months following this intervention. Pender's Health Promotion Model (1987) provided the conceptual basis for development of the training program. A total of 837 highnoise-exposed workers were included in the analysis: 652 regional Midwestern construction workers and 185 national plumber/pipefitter trainers. Effectiveness of the intervention was determined through the sequence of analyses recommended by Braver and Braver (1988) for the Solomon Four-Group Design. Analysis of variance and covariance of postintervention use and intention to use HPDs and a meta-analytic test were done. These analyses indicated that the intervention significantly increased use of HPDs but had no effect on intention to use HPDs in the future. Pretesting had no effect on use. Actual or potential applications of this research include guidance in the development of successful theorybased interventions to increase use of HPDs.
\end{abstract}

\section{INTRODUCTION}

The National Institute for Occupational Safety and Health (NIOSH) estimates that exposure to hazardous noise in the workplace is a problem for more than 30 million workers in the United States (NIOSH, 1996a). The Occupational Safety and Health Administration (OSHA) has mandated hearing conservation programs and safety standards related to work site noise (U.S. Department of Labor, 1983). As part of this standard, employers are required to use engineering or administrative controls whenever possible to reduce noise. When it is not possible to achieve these controls, hearing protection devices (HPDs) should be used to prevent noise-induced hearing loss (NIHL). Noise exposure and subsequent hearing loss are reduced by the use of HPDs - namely, ear plugs and ear muffs (Sataloff \& Sataloff, 1986; Savell \& Toothman, 1987).

Prior studies have examined the efficacy of HPDs (Abel, Alberti, Haythornwaite, \& Riko, 1982; Berger, 1980; Sataloff \& Sataloff, 1986), but relatively few have examined factors related to workers' use of HPDs. Although no comprehensive database is available regarding the extent of use of HPDs, it has been shown that many workers do not use HPDs on a regular basis. In a study of factory workers, Lusk, Ronis, and Baer (1995) found inadequate HPD use in high-noise environments (observed $M=54 \%$, self-reported $M=62 \%$ ). Additionally, in an earlier phase of the study reported here, construction workers reported even lower use of HPDs (operating engineers $M=49 \%$, carpenters $M=18 \%$, plumber/pipefitters $M=31 \%$; see Lusk, Kerr, \& Kauffman,

Send correspondence to Sally L. Lusk, School of Nursing, University of Michigan, 400 N. Ingalls, Rm. 3182, Ann Arbor, MI 48109-0482. HUMAN FACTORS, Vol. 41, No. 3, September 1999, pp. 487-494. Copyright @ 1999, Human Factors and Ergonomics Society. All rights reserved. 
1998). However, work site characteristics differ in a number of ways for construction workers as compared with factory workers, and many factors unique to the construction industry affect workers' use of HPDs.

As a group, construction workers have the highest rates of work-related injury and illness in the United States (U.S. Bureau of the Census, 1995). Among these injuries, NIHL is the most common occupational hazard faced by these workers (Center to Protect Workers' Rights, 1998); about 500000 construction workers are exposed daily to harmful levels of noise (NIOSH, 1996b). In many cases, these workers are employed by more than one firm or work at multiple job sites each day. Construction workers are also exposed to varying amounts of noise, not only from their own equipment and activities but also from the tools and activities of others working around them (Franks, 1990; Hager, 1998). Noise on a construction site is less amenable to engineering controls than is noise in the manufacturing sector, and construction workers may have little control over their environment. Although OSHA mandates hearing conservation programs for factory workers (U.S. Department of Labor, 1983), the standard for the construction industry (29CFR 1926.52) is less comprehensive because it lacks specificity regarding the nature of an effective hearing conservation program (U.S. Department of Labor, 1995). These factors increase the need for the individual worker to take greater personal responsibility for his or her own safety and health than may be necessary in other types of workplaces (Lusk, Ronis, \& Hogan, 1997; Schneider \& Susie, 1993).

In a workshop on behavior change, Fishbein and associates (1991) emphasized the need for all behavioral intervention programs to be guided by a theoretical framework. They outlined three steps in developing effective behavior change interventions: (a) use a conceptual model to identify and measure the variables that predict the target behavior, (b) examine associations among variables and between the variables and the target behavior to identify the strongest predictors, and (c) use the identified predictors to develop the core of an interventional behavior-change program. Further, in a review of 24 studies of personal safety behav- ior, McAfee and Winn (1989) found that none of the studies relied on a conceptual model to explain individuals' performance of safety behaviors. These authors recommended that a conceptual model that includes both cognitive and psychosocial factors be used to predict personal safety behaviors such as the use of hearing protection.

In this study, the Health Promotion Model (HPM; Pender, 1987) was used as the theoretical framework for predicting individual healthpromoting behaviors - specifically, the use of HPDs. Derived from social learning theory, this model contains both cognitive-perceptual and modifying factors that are used to explain individual behavior regarding health promotion. The model postulates that modifying factors (demographics, interpersonal, and situational factors) influence cognitive-perceptual factors (importance of health, perceived control of health, perceived self-efficacy, definition of health, perceived health status, perceived benefits of health-promoting behaviors, and perceived barriers to health-promoting behavior) that in turn influence individuals' healthpromoting behaviors. An earlier study testing the HPM demonstrated that it predicted exercise behavior (Pender, Walker, Sechrist, \& Frank-Stromborg, 1990). In studies of HPD use among factory and construction workers, the model accounted for approximately onehalf the variance in use (Lusk, Ronis, \& Hogan, 1997; Lusk, Ronis, Kerr, \& Atwood, 1994). In an earlier phase of the study reported here, the HPM was used to identify the predictors of construction workers' use of HPDs. Once these predictors were identified, they were used to develop a training program to address the specific needs and concerns of construction workers (Lusk, Kerr, Ronis, \& Eakin, 1999). The purpose of the current study was to measure the effect of this training program, developed to increase the use of HPDs by construction workers.

\section{METHOD}

\section{Subjects}

A regional sample of Midwestern construction workers and a national sample of plumber/pipefitter trainers were recruited to 
participate in the study. For the regional group, a sample of carpenters $(n=343)$, operating engineers $(n=420)$, and plumber/pipefitters $(n=330)$ was recruited from workers scheduled to attend trade association classes. A national sample of 408 plumber/pipefitter trainers was recruited from attendees at a national certification conference. Workers were randomly assigned, usually by naturally occurring training groups, to conditions in a Solomon FourGroup Design depicted as follows:

$\begin{array}{rrr}\mathrm{O} & \mathrm{X} & \mathrm{O} \\ \mathrm{O} & \mathrm{X} & \mathrm{O} \\ & & \mathrm{O}\end{array}$

The Solomon Four-Group Design is one of the strongest research designs. In addition to high internal validity for testing the effect of the intervention, this design also allows an examination of external validity by determining whether the effect of the intervention is different among subjects who have and have not been pretested (Campbell \& Stanley, 1963).

The retention rate of the sample (a percentage calculated by dividing the number of participants at posttest by the number originally recruited at pretest) was $68 \%(1028 / 1501)$. Retention rates for each group were as follows: carpenters, 61\% (208/343); operating engineers, $85 \%$ (356/420); regional plumber/pipefitters, $71 \%(234 / 330)$; and national plumber/ pipefitter trainers, 56\% (230/408).

Because hearing protection devices are needed only during exposure to high noise, the analysis was limited to workers who reported such exposure. Of the sample, 81\% (837/ 1028 ) reported that they were exposed. The proportions of noise-exposed workers for the four groups were as follows: carpenters, 79\% (164/208); operating engineers, $79 \%$ (288/356); regional plumber/pipefitters, $86 \%(200 / 234)$; and national plumber/pipefitter trainers, $65 \%$ $(185 / 230)$.

\section{Dependent Variables}

Two dependent variables were examined in this study. Frequency of use of HPDs when in high noise and intention to use HPDs in the future when in high noise were assessed by selfreport. Use of HPDs was defined as wearing earplugs or earmuffs. High noise was defined as the need to shout to be heard by another person three feet away or closer. The first dependent variable, frequency of use of HPDs, was measured by five questions regarding the percentage of time $(0 \%-100 \%)$ that the worker reported use of HPDs in two job sites (most recent and previous) and three periods (during the past week, past month, and past three months) when in high noise. Because of strong correlations among these five items $(r=.67$ to $r=.94, p<.001$ ), the average score of the five items was used as the dependent variable. The second dependent variable, intention to use HPDs in the future, was measured by a single question asking the participants about the percentage of time $(0 \%-100 \%)$ they intended to use HPDs when exposed to high noise at a job site in the future.

\section{Intervention Program}

The intervention to promote the use of HPDs by construction workers was developed based on significant predictors of construction workers' use of hearing protection found in an earlier phase of this study (Lusk, Kerr, Ronis, \& Eakin, 1999). The program, which was designed to meet the needs and concerns of this particular group of workers, also meets the training requirements set forth in the federal Noise Exposure Standard (U.S. Department of Labor, 1983).

The training program consisted of a 20-min video in addition to guided practice, written handouts, and samples of HPDs. The first half of the video included a discussion between the worker/narrator and an occupational health nurse. This section gave the rationale for use and the information needed to start practicing the use of HPDs.

Following the first half of the video, the program led participants, with the aid of a trainer, through 15 min of hands-on practice with various types of HPDs. The final half of the video showed workers sharing hearing protection information with one another and afforded participants a chance for additional exercises with the video, thus maintaining the interactive approach. 
The entire intervention was presented in a manner that encouraged a great deal of handson activity. The script was designed with this approach in mind. Guided practice in the use of HPDs, using Bandura's (1986) concept of guided mastery experience, was incorporated into the videotape. Social modeling of positive attitudes and perceptions related to use of hearing protection, and active participation in one's hearing health, were demonstrated throughout the video. In addition, social modeling of characters in the videotape engaged the participants in experiences with hearing protection. For example, through the eyes and ears of coworker/actors, viewers were able to experience vicariously the benefits of using HPDs, successful elimination of barriers, and increased confidence in the use of HPDs.

Four trainers guided the training sessions. They, along with the rest of the research team, developed and tested the script for directing the introductory, practice, and closing sessions of the intervention. Intertrainer reliability was maintained through two mechanisms. Two trainers participated in each intervention session with one acting as the leader and the other as the assistant on a rotating basis. In addition, immediately following each session, the two trainers and any additional assistants for that session conducted a debriefing session and completed written field notes. This system ensured ongoing involvement, communication regarding the process, and consistency of sessions.

\section{RESULTS}

\section{Characteristics of the Sample}

Table $1(N=837)$ summarizes demographic, hearing, and noise-related characteristics, as well as use of HPDs as reported at the posttest. Significant differences among the four groups were found for some demographic characteristics, including age, $F(3,826)=$ $241.61, p<.001$; years in trade, $F(3,816)=$

TABLE 1: Characteristics of Noise-Exposed Construction Workers (Posttest Data; $N=837$ )

\begin{tabular}{|c|c|c|c|c|}
\hline & $\begin{array}{l}\text { Carpenters } \\
(n=164)\end{array}$ & $\begin{array}{l}\text { Regional } \\
\text { Operating } \\
\text { Engineers } \\
(n=288)\end{array}$ & $\begin{array}{l}\text { Plumber/ } \\
\text { Pipefitters } \\
(n=200)\end{array}$ & $\begin{array}{l}\text { National } \\
\text { Plumber/ } \\
\text { Pipefitters } \\
\text { Trainers } \\
(n=185)\end{array}$ \\
\hline Demographics & $M(S D)$ & $M(S D)$ & $M(S D)$ & $M(S D)$ \\
\hline $\begin{array}{l}\text { Age* } \\
\text { Years in trade* } \\
\text { Years as journeyman* } \\
\text { Years as apprentice* }\end{array}$ & $\begin{array}{l}27(6) \\
4(4) \\
1(3) \\
3(1)\end{array}$ & $\begin{array}{l}44(9) \\
20(9) \\
16(10) \\
1(2)\end{array}$ & $\begin{array}{l}31(7) \\
5(5) \\
2(5) \\
3(1)\end{array}$ & $\begin{array}{l}42(7) \\
19(7) \\
15(7) \\
5(1)\end{array}$ \\
\hline $\begin{array}{l}\text { Gender: Male } \\
\text { Ethnicity: White }\end{array}$ & $\begin{array}{l}97 \\
89\end{array}$ & $\begin{array}{l}98 \\
93\end{array}$ & $\begin{array}{l}96 \\
93\end{array}$ & $\begin{array}{l}98 \\
96\end{array}$ \\
\hline $\begin{array}{l}\text { Noise and hearing } \\
\text { loss variables }\end{array}$ & & & & \\
\hline $\begin{array}{l}\text { Perceived } \\
\quad \text { hearing loss* } \\
\text { Had hearing test* } \\
\text { Hearing loss on test* } \\
\text { Noise at recent job* }\end{array}$ & $\begin{array}{l}59 \\
64 \\
15 \\
78\end{array}$ & $\begin{array}{l}76 \\
82 \\
56 \\
85\end{array}$ & $\begin{array}{l}61 \\
80 \\
24 \\
70\end{array}$ & $\begin{array}{l}75 \\
71 \\
47 \\
69\end{array}$ \\
\hline $\begin{array}{l}\text { HPD variables }{ }^{a} \\
\text { Use of HPDs } \\
\text { Intended future } \\
\text { use of HPDs* }\end{array}$ & $\begin{array}{l}M(S D) \\
35(33) \\
44(37)\end{array}$ & $\begin{array}{l}M(S D) \\
62(34) \\
78(31)\end{array}$ & $\begin{array}{l}M(S D) \\
42(32) \\
61(31)\end{array}$ & $\begin{array}{l}M(S D) \\
51(34) \\
73(32)\end{array}$ \\
\hline
\end{tabular}

* Significantly different among four groups.

a Measured as percentage of time (0\%-100\%) 
304.30, $p<.001$; years as journeyman, $F(3$, $697)=197.31, p<.001$ and years as apprentice, $F(3,746)=196.65, p<.001$. As shown in Table 1, operating engineers and carpenters constituted the oldest and the youngest groups, respectively. Corresponding with their older age, operating engineers and national plumber/ pipefitter trainers had longer experience in the trade and as journeymen than did the younger regional plumber/pipefitters and carpenters. However, operating engineers had the shortest experience as apprentices in comparison with the other three groups. The four groups did not differ in relation to other demographics, such as gender and ethnicity.

There were also significant differences among the four groups for perceived hearing loss, $\chi^{2}(3, N=829)=22.83, p<.001$; ever having had a hearing test, $\chi^{2}(3, N=832)=$ $21.40, p<.001$; reported hearing loss on the hearing test, $\chi^{2}(3, N=598)=66.24, p<.001$; and noise exposure at recent job, $\chi^{2}(3, N=$ $830)=21.52, p<.001$. As can be seen in Table 1, operating engineers and national plumber/pipefitter trainers showed more hearing loss both by self-report and on the selfreported results of a hearing test than did carpenters and regional plumber/pipefitters. Operating engineers reported more noise exposure at their most recent job than did the other three groups. A previous study by Lusk, Ronis, and Baer (1995) showed that self-report of factory workers' use of hearing protection correlated with observation at $\mathbf{8 9}$. This finding gives credence to the use of the self-report measure and validates its use as the measure of the dependent variable. Because of this reliability and the relative cost-efficiency and timeefficiency, self-report was considered to be the optimum measure for this variable.

The four groups also showed significant differences in use of HPDs, $F(3,830)=28.32$, $p<.001$, and intended future use of HPDs, $F(3,824)=42.05, p<.001$. Operating engineers showed the highest rate for both use $(62 \%)$ and intention to use HPDs $(78 \%)$. Carpenters had the lowest scores for both use of $(35 \%)$ and intention to use HPDs $(44 \%)$ among the four groups.

Correlations among variables demonstrated that age and two age-related variables (years in trade and years as journeyman) were significantly associated with postintervention HPD use and intention to use HPDs in the future ( $r=$ $.13-.23, p<.05)$. The older workers with more work experience used HPDs a greater portion of the time and reported higher intention to use HPDs in the future. Both pretest use and pretest intention to use HPDs were also significantly related to the use of HPDs and to intended future use of HPDs at postintervention $(r=.33-.58, p<.05)$.

\section{Effects of Intervention, Pretesting, and Trade Group on Posttest Use}

Braver and Braver (1988) provided detailed analyses designed for a Solomon Four-Group Design, including a conditional sequence of successive analyses. The first step is to conduct a 2 (intervention vs. no intervention) $\times 2$ (pretested vs. not pretested) analysis of variance (ANOVA) on the dependent variable. If there is a significant main effect of the intervention, and no significant interaction with pretesting, there are no additional steps. This result would mean that the intervention had an effect that was not significantly different for those who were and those who were not pretested. Other results, such as those encountered later in analyses of intention to use HPDs, lead to various additional steps.

Because of notable differences in several characteristics and use of HPDs by the four trade groups, trade group membership was included in the analysis, yielding a 2 (intervention vs. no intervention) $\times 2$ (pretested vs. not pretested) $\times 4$ (trade group) ANOVA. Mean posttest use of HPDs was the dependent variable. The ANOVA found a significant main effect of the intervention, $F(1,818)=7.86, p=$ .005 , a significant main effect of trade group, $F(3,818)=27.87, p<.001$, no significant effect of pretesting, $F(1,818)=.32, p=.574$, and no significant interactions (all interactions $p>.1)$. Thus the intervention had a significant effect on use of HPDs that was not significantly different for workers who were and were not pretested and for workers in different trade groups. Among workers who participated in both the pretest and intervention $(n=192)$, the intervention was responsible for a $20 \%$ improvement over baseline (pretest) use, 
Table 2: Posttest use of HPDs ${ }^{a}$ among non-intervention and intervention groups of noise-exposed workers $(\mathrm{n}=837)$

\begin{tabular}{|c|c|c|c|c|c|c|}
\hline \multirow[b]{2}{*}{ Trade group } & \multicolumn{3}{|c|}{ Nonintervention } & \multicolumn{3}{|c|}{ Intervention } \\
\hline & $n$ & $M$ & $(S D)$ & $n$ & $M$ & $(S D)$ \\
\hline \multicolumn{7}{|l|}{ Regional } \\
\hline Carpenters & 80 & 35 & (33) & 84 & 34 & (33) \\
\hline Operating Engineers & 142 & 61 & (34) & 144 & 64 & (34) \\
\hline Plumber/pipefitters & 93 & 35 & (30) & 107 & 48 & (32) \\
\hline \multicolumn{7}{|l|}{ National } \\
\hline Plumber/pipefitters & 86 & 44 & (35) & 98 & 56 & (32) \\
\hline Total & 401 & 46 & (35) & 433 & 52 & (35) \\
\hline
\end{tabular}

${ }^{\text {a }}$ Measured as percentage of time (0\%-100\%)

increasing use of HPDs from $44 \%$ to $53 \%$ of the time they should be used.

Posttest use by trade and intervention is shown in Table 2. On average, workers receiving the intervention (some pretested and some not) reported use of HPDs a higher proportion of the time $(52 \%)$ than workers not receiving the intervention $(46 \%)$. Because the intervention had a significant effect and there were no significant interactions, the Solomon FourGroup Design analysis (Braver \& Braver, 1988) for this dependent variable was complete.

\section{Effects of Intervention, Pretesting, and Trade on Intended Future Use}

The first step in the analysis of intended future use was the same sort of 2 (intervention vs. no intervention) $\times 2$ (pretested vs. not pretested) $\times 4$ (trade group) ANOVA as used earlier. The dependent variable was intended future use of HPDs when in high-noise situations. The ANOVA showed no main effects of pretesting or intervention, and none of the interactions were significant (each $p>.1$ ). The only significant effect in this ANOVA was the main effect of trade group, $F(3,812)=40.82, p<.001$.

In this situation (no main effect of intervention and no Pretesting $\times$ Intervention interaction in the ANOVA on posttests), the next step in the Braver and Braver (1988) analysis of a Solomon Four-Group Design is to conduct a test of the effect of the intervention while adjusting for the pretest score in the two pretested groups. Generally analysis of covariance (ANCOVA), using the pretest score on the dependent variable as the covariate, is the most sensitive of these analyses. Therefore a 2 (intervention vs. no intervention) $\times 4$ (trade group) ANCOVA was conducted on intended future use of HPDs among pretested workers using pretest intention as the covariate. The ANCOVA found no significant effect of the intervention, $F(1,398)=.77, p=$ .382. In this situation (no effect of the intervention in pretested groups), the next step in the Braver and Braver procedure is to test this effect in the non-pretested groups. Because of the trade differences, this test was conducted using a 2 (intervention vs. no intervention) $\times 4$ (trade group) ANOVA on posttest intention in the nonpretested groups. The ANOVA found no significant effect of the intervention, $F(1,406)=.03$, $p=.862$.

The final step in the Braver and Braver (1988) analysis plan (after two negative tests of the intervention in the pretested and non-pretested groups) is to apply a meta-analytic method to combine the results of these two tests. This is usually done using Stouffer's z-method (Becker, 1987). The result of Stouffer's z-method was negative $(p=.46)$, leading to the conclusion that the intervention did not increase intention to use HPDs during the one-year follow up. As previously noted, intention tended to be highest among operating engineers and lowest among carpenters (see Table 1).

\section{DISCUSSION}

Clearly the level of use of hearing protection devices by the trade groups of construction 
workers included in this study is inadequate. When in high noise, workers should use HPDs $100 \%$ of the time in order to effectively prevent noise-induced hearing loss (Dear, 1998; Else, 1973). For these subjects, postintervention self-reported use of HPDs ranged from only $34 \%$ to $64 \%$. Although it did not achieve the desired $100 \%$ use when in high noise, the intervention did result in a significant increase in the use of HPDs.

Within the constraints of this study, it was possible only to deliver the intervention and then, 10-12 months later, assess its effects. Although the literature does not clearly identify the ideal timing and frequency of subsequent interventions, there is agreement that limited changes in behavior can be expected from a "one-shot" intervention. Clearly, the long delay from intervention to postuse measure allows for dissipation of the effect of the intervention. Attention should be directed to the optimum frequency and timing of followup interventions in order to achieve the desired effect.

Although the change in use of HPDs was not as large as would have been desired, any increase in use of HPDs contributes to reduced noise exposure and decreased NIHL. Given the recognized limitations of one-shot interventions, it may be considered remarkable that, based upon an intervention delivered 10-12 months earlier, HPD use did change. We believe that the multifaceted nature of the intervention tested in this study contributed to its success, as it addressed a number of behavioral issues and offered practice and feedback to enhance the adoption of the behavior.

However, this study did not test an intervention that was tailored to the interests or beliefs of the individual. Prochaska and DiClemente (1992) suggested that interventions should be tailored to the individual's readiness to change, with different content and approaches depending on her or his current status in one of five stages of change. These stages range from precontemplation of behavior (have not considered performing behavior) to maintenance of behavior. Future studies of HPD use should strive to assess the individual's readiness for changing behavior and should deliver an intervention tailored to her or his stage of change.
The fact that younger workers used HPDs less often and reported lower intention to use HPDs in the future is distressing for what it portends for the future. It is essential that young workers consistently use HPDs to prevent the negative effects on hearing resulting from cumulative noise exposures. The results for construction workers cannot be separated from the effect of trade group membership (operating engineers made up the oldest group and used hearing protection more often, whereas carpenters were the youngest group and used hearing protection less that the other trades). If the reduced use of HPDs by younger construction workers continues, the desired reduction in incidence of NIHL will not be seen in this worker population.

It was beyond the confines of this study to assess hearing ability, and hearing tests reported by the workers may have been administered many years ago. This is the likely explanation for the difference between workers' report of hearing loss on a test $(15 \%-56 \%)$ and perceived hearing loss $(59 \%-76 \%)$. Future studies of HPD use should incorporate audiometric testing for an accurate assessment of hearing ability.

In summary, this project is the first study to assess the effectiveness of an intervention for increasing construction workers' use of HPDs. The intervention did significantly increase use of HPDs, but not to the desired level of $100 \%$ use when in high-noise environments. Future studies are needed to further understand the job factors affecting HPD use, the optimum timing and frequency of interventions, and the mechanisms required to tailor the intervention according to individuals' readiness to change. Increasing HPD use is essential to preventing NIHL in construction workers.

\section{ACKNOWLEDGMENTS}

This study was supported by Grant OH03136 from the National Institute for Occupational Safety and Health.

\section{REFERENCES}

Abel, S. M., Alberti, P. W., Haythornwaite, C., \& Riko, K. (1982), Speech intelligibility in noise: Effects of fluency and hearing protector type. Journal of the Acoustical Society of America, $71,708-715$. 
Bandura, A. (1986). Social foundations of thought and action: A social cognitive theory. Mahwah, NJ: Prentice-Hall.

Becker, B. J. (1987). Applying tests of combined significance in meta-analysis. Psychological Bulletin, 102, 164-171.

Berger, E. H. (1980). The effects of hearing protectors on auditory communications. Occupational Health Nursing, 28 (1), 6-7.

Braver, M. C. W., \& Braver, S. L. (1988). Statistical treatment of the Solomon Four-Group Design: A meta-analytic approach. Psychological Bulletin, 104, 150-154.

Campbell, D., \& Stanley, J. (1963). Experimental and quasiexperimental designs for research. Boston: Houghton Mifflin.

Center to Protect Workers' Rights. (1998). The construction chart book: Noise-induced hearing loss in construction. Washington, DC: U.S. Government Printing Office.

Dear, T. A. (1998). Updating damage risk criteria to include performance under workplace noise regulations. Journal of Occupational Hearing Loss, 1(1), 61-66.

Else, D. (1973). A note on the protection afforded by hearing protectors - Implications of the energy principle. Annals of Occupational Hygiene, 16(1), 81-83.

Fishbein, M., Bandura, A., Triandis, H., Kanfer, F., Becker, M., \& Middlestadt, S. (1991, October). Factors influencing behavior and behavior change (Final Report). Washington, DC: Theorist's Workshop.

Franks, J. R. (1990). Noise in the construction industry and its effect on hearing. Hearing Instruments, 41: 18-21.

Hager, L. D. (1998). Sound exposure profiling: A noise monitoring alternative. American Industrial Hygiene Association Journal, 59, 414-418.

Lusk, S., Kerr, M., \& Kauffman, S. (1998). Use of hearing protection and perceptions of noise exposure among construction workers. American Industrial Hygiene Association Journal, 59, 466-470.

Lusk, S., Kerr, M., Ronis, D., \& Eakin, B. (1999). Applying the Health Promotion Model to development of a work site intervention. American Journal of Health Promotion, 13 (4), 219-227.

Lusk, S., Ronis, D., \& Baer, L. (1995). A comparison of multiple indicators: Observations, supervisor report, and self-report as measures of workers' hearing protection use. Evaluation and the Health Professions, 18, 51-63.

Lusk, S., Ronis, D., \& Hogan, M. (1997). Test of the Health Promotion Model as a causal model of construction workers' use of hearing protection. Research in Nursing \& Health, 20, 183-194.

Lusk, S., Ronis, D., Kerr, M., \& Atwood, J. (1994). Test of the health promotion model as a causal model of workers' use of hearing protection. Nursing Research, 43(3), 151-157.

McAfee, R., \& Winn, A. (1989). The use of incentives/feedback to enhance workplace safety: A critique of the literature. Journal of Safety Research, 20, 7-19.

National Institute for Occupational Safety and Health (NIOSH) (1996a). National occupational research agenda. Washington, DC: U.S. Department of Health \& Human Services, Public Health Service, Centers for Disease Control and Prevention.

National Institute for Occupational Safety and Health, (NIOSH). (1996b). An evaluation of the national program for occupational safety and health in construction. Washington, DC: U.S. Department of Health \& Human Services, Public Health Service, Centers for Disease Control and Prevention.

Pender, N. (1987). Health promotion in nursing practice (2nd ed.). Norwalk, CT: Appleton \& Lange.

Pender, N., Walker, S., Sechrist, K., \& Frank-Stromborg, M. (1990). Predicting health-promoting lifestyles in the workplace. Nursing Research, 39(6), 326-332.

Prochaska, J. O., \& DiClemente, C. C. (1992). Stages of change in the modification of problem behaviors. Progress in Behavioral Modification, 28, 183-218.

Sataloff, R., \& Sataloff, R. T. (1986). Documenting hearing conservation test equipment's effectiveness. Occupational Health and Safety, 55(2), 28, 29, 32-33, 35-36.
Savell, J., \& Toothman, E. (1987). Group mean hearing threshold changes in a noise-exposed industrial population using personal hearing protectors. Journal of the Acoustical Society of America, 48, 23-27.

Schneider, S. S., \& Susie, P. (1993). Final Report: An investigation of health hazards on a new construction project. Washington, DC: Center to Protect Workers' Rights.

U.S. Bureau of the Census. (1995). Statistical abstract of the United States (115th ed.). Washington, DC: U.S. Government Printing Office.

U.S. Department of Labor. (1983, March 8). Occupational noise exposure: Hearing conservation amendment: Final rule. Federal Register, 48(46).

U.S. Department of Labor, Occupational Safety and Health Administration. (1995). Construction Industry Digest. Washington, DC: U.S. Government Printing Office.

Sally L. Lusk received her Ph.D. in educational psychology from the University of Michigan. She is a professor, director of the occupational health nursing program, and director of post-doctoral training in health promotion and risk reduction interventions research in the School of Nursing at the University of Michigan.

Oi Saeng Hong received her Ph.D. in nursing science from the University of Illinois at Chicago. She is a postdoctoral research fellow in the Division of Health Promotion and Risk Reduction Programs, University of Michigan School of Nursing.

David L. Ronis received his Ph.D. in psychology from Ohio State University, and had postdoctoral training at the University of Michigan. He is director of the Statistical Consulting Team at the University of Michigan School of Nursing and also holds a position in the Health Services Research and Development Field Program of the U.S. Department of Veterans Affairs.

Brenda L. Eakin received her M.S. in public health education from the California College for Health Sciences. She is project manager for an NIH-funded study focused on preventing noise-induced hearing loss among factory workers at the University of Michigan School of Nursing.

Madeleine J. Kerr received her Ph.D. in clinical nursing research from the University of Michigan. She is an assistant professor of nursing at the University of Minnesota School of Nursing.

Margaret R. Early received her Ph.D. in clinical nursing research from the University of Michigan. She is an assistant professor of nursing at Oakland University School of Nursing.

Date received: September 10, 1998

Date accepted: February 5, 1999 